Pensamiento Crítico N. ${ }^{\circ} 11$, pp. 111-122

\title{
Característica de las economías actuales: el intervencionismo
}

\author{
Pablo Rivas Santos
}

\section{RESUMEN}

El presente artículo demuestra que el sistema económico intervencionista es inherente a la mayoría de las economías de los países del mundo, pese a sus medidas que perturban la mecánica de mercado no aspira a borrar esa dualidad: la actividad estatal y el mercado.

El problema consiste en determinar quién va a planear y dirigir. Si será cada persona, de acuerdo con sus juicios de valor, o será el paternal gobernante a nombre de todos. El dilema está en optar entre el actuar libre e independiente de la persona o la sumisión de la persona a las decisiones inapelables del gobierno. Se trata de elegir entre libertad y dictadura. El dejar hacer pretende dejar a todos en libertad para que cada uno decida cómo va a cooperar en la división social del trabajo; y que sean los consumidores quienes determinen lo que los empresarios hayan de producir. La planificación supone autorizar al gobernante para que, por sí y ante sí, amparado en los resortes de la represión, resuelva e imponga.

Toda injerencia estatal en la esfera del mercado, indirectamente repercute sobre el consumo, por cuanto altera el mecanismo del mercado; toda injerencia estatal influye en la conducta y consideraciones valorativas de los consumidores. El intervencionismo siempre engendra corrupción.

Palabras clave: Economía de mercado, intervencionismo, dejar hacer, dualidad. 


\title{
Pablo Rivas Santos
}

\begin{abstract}
This paper shows that the interventionist economic system is inherent in most of the economies of countries in the world, since the intervention, despite his actions that disrupt the market mechanism does not strive to remove this duality that exists in the market economy the state and market activity.

The problem is to determine who will plan and lead. If each person will be in accordance with their value judgments, or be the ruler paternal name of all. The dilemma is choosing between the free and independent act of the person or the submission of the person subject to ap.eal government decisions. It is a choice between freedom and dictatorship. The laissez-faire is intended to make free for all: each will decide how to cooperate in the social division of labor, and who are the consumers who determine what employers have to produce. The planning involves the governor to authorize, for and of itself, protected by the springs of repression, resolve and enforce. All state interference in the market sphere, indirectly impact on consumption. Because altering the market mechanism, government interference and influences the behavior of consumers considered securities. Interventionism always breeds corruption.
\end{abstract}

Keywords: Market economy, interventionist, laissez-faire, duality.

\section{INTRODUCCIÓN}

Está definida la frontera que separa el sistema económico basado en la propiedad privada de los factores de producción (economía de mercado) del sistema basado en la propiedad estatal de los factores de producción (estatismo). Ambos sistemas admiten exacta definición; no cabe combinarlos; no es posible gradual evolución que del uno conduzca al otro; son mutuamente contradictorios. Unos mismos factores de producción o son poseídos privadamente o son poseídos estatalmente. El que en una economía determinados factores de producción sean de propiedad privada mientras que otros factores de producción sean de propiedad estatal, no argumenta la existencia de un sistema mixto en parte economía de mercado y en parte estatista. Tal economía es de mercado; siempre que el sector estatal no se desvincule de la economía de mercado y lleve una vida separada y autónoma. (En tal caso nos hallamos ante dos sistemas separados -economía de mercado y estatismo- coexistiendo paralelamente). Las empresas estatales en países con economía de mercado operan bajo el dominio del 


\section{Característica de las economías actuales: el intervencionismo}

mercado; están sujetas a las leyes del mercado y, por tanto, pueden apelar al cálculo económico.

Si queremos estructurar entre los dos sistemas, un tercer sistema de cooperación social bajo el signo de la división del trabajo, partiremos de la economía del mercado. En la economía de mercado; esa dualidad: mercado y gobierno monopolizador de la fuerza y coacción sugiere ideas y fórmulas diversas.

\section{EL INTERVENCIONISMO}

Por dos caminos cabe llegar al estatismo. El primer camino (el sistema norcoreano) es puramente burocrático. Todas las actividades productivas quedan estatizadas; las empresas son simples departamentos administrativos, operados por funcionarios públicos.

El segundo camino (el sistema intervencionista) nominalmente mantiene la propiedad privada de los factores de producción; y un aparente mercado con supuestos precios, salarios y tasas de interés. Sin embargo, el empresario ha sido suprimido, subsistiendo tan solo jefes de empresa. Los jefes de empresa dirigen y ordenan las empresas encomendadas a ellas; compran y venden; contratan y despiden personal; conciertan operaciones financieras; pagan intereses y amortizan créditos. Sin embargo, en dichas actuaciones se ven obligados a seguir las directivas que le señala el gobierno.

El gobierno instruye a los jefes de empresa acerca de qué y cómo deben producir; a qué precio y dónde deben comprar; a quienes deben vender. Cada uno encuentra predeterminado el puesto de trabajo a desempeñar y el salario a percibir. El mercado es una ficción. Solo el gobierno determina salarios, precios y tasas de interés; solamente, en sentido formal, cabe considerar salarios, precios e intereses; son puras expresiones cuantitativas manejadas por la administración para determinar el trabajo, salarios, consumo y nivel de vida de cada ciudadano. El gobierno por sí y ante sí, ordena y encauza toda la actividad productiva. Los jefes de empresa obedecen y cumplen las órdenes del gobierno, sin que para nada influyan los deseos y apetencias de los consumidores; no determinando ya los consumidores los precios de mercado y la producción. Estamos ante un socialismo que pretende ocultarse tras la máscara de la economía de mercado. 


\section{Pablo Rivas Santos}

Bajo el intervencionismo (la economía de mercado intervenida) todavía subsiste el mercado. El gobierno interfiere y perturba la operación del mercado, pero todavía no lo ha eliminado completamente. El intervencionismo, pese a sus medidas perturbadoras de la mecánica de mercado, no aspira a borrar esa dualidad que existe bajo la economía de mercado: la actividad estatal y el mercado. Lo que caracteriza al intervencionismo es que el Estado interfiere la vida de mercado con mandatos y prohibiciones.

El intervencionismo consiste en una orden directa o indirecta formulada por quien detenta la fuerza pública; orden que obliga a empresarios y capitalistas a explotar determinados factores de producción de manera distinta a como los explotarían bajo el dominio del mercado. Si el gobierno permite respaldándolas o no (con las Fuerzas Armadas) tales actuaciones; estas actuaciones quedan asimiladas a las directas medidas estatales.

La acción del Estado supone la violencia o la posibilidad de imponerla. El dinero que el gobierno invierte en sus actividades han sido previamente sustraídas a las personas mediante los correspondientes despojos tributarios. El gobierno consigue tal cantidad de dinero por cuanto los contribuyentes no se atreven a poner resistencia al gobierno, al constarle que sería inútil su oposición. El Estado, mientras así tenga planteadas las cosas puede conseguir de sus súbditos cuanto dinero desee gastar. El gobernar implica, en última instancia, apelar a las armas; policías; soldados y cárceles. Lo que caracteriza al gobierno es que quien lo detenta puede imponer su voluntad castigando o encarcelando al opositor. Quienes reclaman mayor intervención estatal están postulando más imposición y menos libertad.

Esto no implica enjuiciar ni condenar la existencia del Estado, ya que no es posible la pacífica cooperación social en ausencia de un instrumento que prevenga, por la fuerza incluso si es necesario, las actuaciones de grupos o individuos antisociales.

\section{LA FUNCIÓN DEL ESTADO}

El bien y el mal son conceptos humanos, útiles expresiones arbitradas con la finalidad de hacer posible la cooperación social bajo el signo de la división del trabajo. Los hombres decretan las Normas Morales y Leyes Civiles con el deseo de conseguir específicos objetivos. Solo ponderando previamente su oportunidad para alcanzar los fines deseados, cabe calificar de buena o mala la norma legal. 


\section{Característica de las economías actuales: el intervencionismo}

Estado y gobierno son medios. Las autoridades recurren a la fuerza y coacción únicamente para implantar y mantener determinado sistema económico. La amplitud de la esfera en que haya de aplicarse la fuerza pública; y las normas que la fuerza pública deba hacer respetar, vienen determinadas por el sistema económico que se quiera adoptar. El Estado tiene la misión de permitir la pacífica sobrevivencia del correspondiente sistema económico; y la determinación de las legítimas funciones sociales dependerá de cuáles sean los cometidos encomendados al gobierno. Para enjuiciar la legislación y las medidas adoptadas con la finalidad de que tal legislación se respete, es necesario examinar previamente si la legislación y las medidas adoptadas son idóneas para mantener el sistema económico deseado.

Solo a la luz del preexistente sistema económico cabe enjuiciar la justicia o injusticia de específica actuación.

Cuando se trata de alterar, reformar o derogar las vigentes normas legales; o decretar nuevas normas legales; lo único que cabe ponderar es la utilidad o conveniencia social de tales normas legales. Es necesario referirse a determinado sistema económico para que cobre sentido el concepto de justicia. Es el sistema económico preferido el que nos indica qué actos son buenos y cuáles son malos. La idea de justicia cobra sentido al surgir la cooperación social.

El gobernante goza de poder suficiente para implantar, en el territorio dominado, el más absoluto régimen totalitario. Sin embargo, lo que hay que aclarar es si tal régimen, desde el punto de vista social, resulta oportuno y conveniente. Sólo la investigación científica del Estado y el Derecho, permite resolver ese único problema que interesa.

El gobierno no puede fijar precios y castigar a los que contravienen a esos precios, de la misma manera como persigue y sanciona al delincuente. El único fin de las normas legales y el aparato estatal de coacción y violencia es permitir que funcione pacíficamente la cooperación social. El gobierno goza de poder para decretar precios máximos y subsiguientemente castigar e incluso ajusticiar a quien que se atreva a contravenir tales disposiciones. Sin embargo, lo único que interesa aclarar es si tales medidas permiten alcanzar aquellos objetivos que el Estado aspira cuando impone el intervencionismo. Estamos ante la cuestión exclusivamente económica. 


\section{Pablo Rivas Santos}

Al abordar el intervencionismo aclararemos cómo opera y qué efectos provoca. Averiguaremos si el intervencionismo permite alcanzar aquellos objetivos que el Estado quiere conseguir, mediante las correspondientes medidas dirigistas.

La regulación del tránsito vehicular compete al organismo -estatal o municipalque posee y administra tales vías. La empresa de transporte determina el horario y la frecuencia de las salidas de omnibuses, lo mismo que el gerente del hotel es quien decide si habrá música o no durante el almuerzo. Será el gobierno quien resuelva esas cuestiones; si el hotel o el ómnibus es de propiedad estatal. No implica intervencionismo el que el director general de Correos señale el tamaño y color de los sellos. Es el gobierno en un teatro estatal quien decide qué óperas deben darse; sin embargo, de ello, no se sigue que sea el gobierno quien decida ese mismo asunto; si el teatro es de propiedad privada.

Los intervencionistas dicen que no desean eliminar la propiedad privada de los factores de producción; acabar con la actividad empresarial ni destruir el mercado. En este sentido, dicen que la economía de mercado es el más fecundo sistema económico que cabe estructurar. Sin embargo, los intervencionistas rechazan la economía de mercado. Dicen que el Estado debe intervenir, siempre y cuando el "libre juego de las fuerzas económicas" provoque efectos negativos desde un punto de vista "social". Creen que compete al gobierno dictaminar en cada caso qué cosas son y qué cosas no son "socialmente" deseables, quedando la burocracia facultada para determinar si procede o no la intervención estatal.

Los intervencionistas no se dan cuenta que están autorizando al gobierno a interferir toda la actividad económica, lo que conducirá a la implantación del estatismo. Si el gobierno interviene allí donde y cuando lo considere oportuno, ya no hay esfera económica regulada por el mercado. En tal caso, los consumidores han dejado de decidir qué, cómo, cuánto, para quien y dónde debe producirse; es el gobierno quien resuelve tales cuestiones. El gobierno interviene en cuanto el mercado adopta una medida considerada indeseable. El mercado es "libre" mientras actúe tal y como el Estado desea que lo haga; tiene "plena libertad" para realizar lo que el Estado considera "bueno", pero no tiene libertad cuando trata de hacer algo que el Estado considera "malo". Porque es el gobierno, el único competente para definir "lo bueno" y "lo malo". La teoría y la práctica 


\section{Característica de las economías actuales: el intervencionismo}

del intervencionismo van paulatinamente apartándose de aquello que lo distinguía del estatismo; desembocando en poderosa planificación totalitaria.

El intervencionista plantea el dilema entre la economía operada: por "fuerzas ciegas y automáticas" o por una "planificación consciente". El intervencionista dice que confiar en procesos irreflexivos es inútil. Nadie puede propugnar que todo siga su curso sin que intervenga una voluntad pensante. Cualquier ordenamiento racional de la vida económica es superior a la ausencia de todo plan. Por eso, el dejar hacer para el intervencionista significa dejar que perduren las desgracias; no interfieras, no hagas nada por mejorar la suerte de la humanidad dolida.

Sin embargo, el planteamiento es falaz. Tal razonamiento favorable a la planificación deriva de inadmisible expresión. Tiene el significado que se atribuye al vocablo "automático", empleado, en sentido figurado, para explicar la operación del mercado. "Automático" significa cosa "inconsciente, ininteligente, mecánica" y también significa lo "no sujeto al control de la voluntad, realizado sin reflexión mental, sin intención o dirección consciente".

El problema consiste en determinar quién va a planear y dirigir. Si será cada persona, de acuerdo con sus juicios de valor; o será el paternal gobernante a nombre de todos. El dilema está en optar entre el actuar libre e independiente de la persona o la sumisión de la persona a las decisiones inapelables del gobierno. Se trata de elegir entre libertad y dictadura.

El dejar hacer pretende dejar a todos en libertad para que cada uno decida cómo va a cooperar en la división social del trabajo; y que sean los consumidores quienes determinen lo que los empresarios hayan de producir. La planificación supone autorizar al gobernante para que, por sí y ante sí, amparado en los resortes de la represión, resuelva e imponga.

Pero en el mercado, replica el intervencionista, no se producen aquellos bienes que la gente necesita, sino los bienes que dan mayor ganancia; y el objetivo de la planificación debe ser encauzar la producción de manera que queden satisfechas las autenticas necesidades de la gente ¿Alguien sabe cuáles son tales auténticas necesidades? 


\section{Pablo Rivas Santos}

El intervencionista señala como objetivo de la acción estatal "canalizar el ahorro a la construcción de viviendas; que a la construcción de estadios". No interesa que uno pueda coincidir con el intervencionista valorando más la vivienda que el estadio. La realidad es que la gente, mediante la compra de boletos para ir al estadio, expresan diariamente distinta opinión. Si la gente, la misma que con sus votos llevaron al poder al partido populista, en vez de ir a los estadios, hubiera preferido invertir su dinero en la compra de cómodas viviendas, sin necesidad de ningún tutelaje estatal, por impulso puramente lucrativo; la industria de la construcción se hubiera orientado hacia la construcción de viviendas en vez de construir estadios. Lo que, en el fondo, pretende el intervencionista es desafiar la voluntad de la gente y sustituir por sus propias valoraciones los auténticos deseos de la gente. Aspira a eliminar la democracia del mercado e implantar el absolutismo en la producción. Piensa que tiene razón desde un punto de vista "más elevado"; y que, como "superhombre", se halla facultado para imponer su propio criterio a las masas de seres "inferiores".

\section{LA INTERVENCIÓN DIRECTA EN EL CONSUMO}

Toda injerencia estatal en la esfera del mercado indirectamente repercute sobre el consumo, por cuanto altera el mecanismo del mercado; toda injerencia estatal influye en la conducta y consideraciones valorativas de los consumidores. Cuando el gobierno se limita a forzar al consumidor a comprar distintos bienes de los que hubiera preferido en ausencia del mandato gubernamental; no se suscita ningún problema que requiera particular análisis económico. Cualquier mecanismo policiaco fuerte y despiadado dispone de poder suficiente para hacer respetar tal mandato.

Al contemplar la elección realizada por el consumidor, solo consideramos los efectos que provoca tal personal conducta de los consumidores en la determinación de los precios del mercado y consiguientemente en la producción. En la determinación del precio de la papa, lo único que influye es la cantidad de la demanda efectiva.

El gobierno que desea mantener las apariencias externas de libertad, a pesar de procurar cortar la libertad, disimula la injerencia directa en el consumo bajo la capa de intervención en la vida del mercado. La Ley Seca pretendía que los residentes del país no fabriquen ni compren ni transporten licores. Pero hipócritamente esa Ley no 


\section{Característica de las economías actuales: el intervencionismo}

sancionaba el acto de beber. En cambio, lo que prohibía era la fabricación, venta y transporte del licor, es decir, toda la actividad de mercado previa al acto de beber licor. La Ley Seca aspiraba a suprimir la libertad de la gente para gastar su dinero y gozar de la vida a su manera. Las medidas restrictivas impuestas a las industrias eran simples consecuencias del objetivo perseguido.

La directa injerencia estatal sobre el consumo no suscita problemas a la Teoría Económica; va mas allá del ámbito de la Teoría Económica; y atañe al fundamento del sistema económico y de la propia vida humana. Si la autoridad del gobernante procede de Dios, el gobernante debe reglamentar y vigilar celosamente la conducta de las masas. Tal gobernante conoce lo que conviene a las masas mucho mejor de lo que ellos mismos lo saben. Conviene que les evite tan innumerables daños como personalmente se inferirían de dejarles actuar libremente.

Quienes se califican de "realistas" son incapaces de apreciar la trascendencia de estos temas. Opinan que se trata de problemas que no se pueden examinar desde un punto de vista académico. Consideran que "solo la realidad" debe ser tomada en cuenta. Dicen que hay personas que a sí mismas se dañan y perjudican gravemente a sus propios e inocentes deudos mediante el uso de drogas; nadie se puede oponer a que el gobierno regule el tráfico de drogas. Los beneficiosos efectos que derivan de tal intervención son obvios.

Pero el problema no es tan sencillo. La cocaína es una droga nociva que genera hábitos viciosos. Admitido el principio de que "compete al gobierno proteger al individuo contra su propia necedad"; no cabe oponer objeciones serias a ninguna posterior intervención estatal. Lo mismo puede decirse del alcohol. Pero, entonces ¿̇por qué la benévola providencia del gobierno no se extiende más allá del cuidado corporal? El daño que el hombre puede infligir a su mente y a su alma ¿no es, acaso, más perturbador que cualquier padecimiento físico? ¿Por qué no impedirle que lea libros perniciosos y que presencie detestables representaciones teatrales; que contemple pinturas y esculturas reñidas con la estética; y que oigan música horrible? Las consecuencias dañinas que derivan de una ideología social nociva son mucho más perniciosas, tanto para el individuo como para la colectividad; que todas las consecuencias que pudieran derivarse del uso de drogas. 


\section{Pablo Rivas Santos}

Y esto no es producto de la caliente imaginación de asustados y solitarios intelectuales. Porque lo que se necesita advertir es que ningún gobierno intervencionista jamás se abstuvo de reglamentar las ideas, las opiniones y las creencias de sus gobernados. Tan pronto como se cercena la libertad de cada uno, para decidir aquello que personalmente prefiera consumir, todas las demás libertades quedan igualmente suprimidas. Cuantos, ingenuamente, admiten la injerencia estatal en el consumo, se engañan cerrando los ojos a lo que, con menosprecio, denomina aspectos académicos de la cuestión. No advierten que, por tal vía, están convirtiéndose en paladines de la censura, de la inquisición, de la intolerancia religiosa y de la persecución del disidente.

Prescindimos de las consecuencias políticas que acompañan a toda injerencia en el consumo, cuando (desde el punto de vista teórico) analizamos el intervencionismo. Destacamos que empresarios y capitalistas van a tener que aprovechar los factores de producción de modo distinto a como lo hubieran hecho de actuar solo bajo los dictados del mercado. Nos limitamos a determinar si, mediante la injerencia estatal, cabe o no alcanzar aquellos objetivos que desean conseguir quienes propugnan y recurren al intervencionismo.

\section{LA CORRUPCIÓN ADMINISTRATIVA}

Toda intervención estatal en la mecánica del mercado desde el punto de vista de los ciudadanos afectados por esa intervención, se califica como confiscación. La actividad intervencionista da lugar a que ciertos grupos se enriquezcan a costa de otros grupos. Lo que no impide que el daño infligido a unos, a nadie beneficie; saliendo finalmente todos dañados.

Ninguna norma garantiza que sean justas y equitativamente ejercitadas las grandes facultades que el intervencionismo coloca en manos del poder. Los intervencionistas pretenden hacer creer que la actuación del gobernante, siempre sabia y ecuánime, y la actuación de sus servidores, los burócratas, evitarán las perniciosas consecuencias que provocan "desde un punto de vista social", la propiedad individual y la acción empresarial. El hombre común y corriente, para los intervencionistas, es un débil que necesita un paternal tutelaje que le proteja contra las astutas tretas de gente mala. Los partidarios del estatismo se burlan de todo lo que significaron los conceptos de ley y 


\section{Característica de las economías actuales: el intervencionismo}

legalidad, en aras de "una más noble y elevación de la justicia". Los actos de los administradores públicos están autorizados; esa justicia sui generis que se invoca les faculta para sancionar a quienes ellos entiendan haberse apropiado egoístamente de lo que pertenecía a otros.

El hombre, al actuar, aspira a provocar una situación que él aprecia en más que la situación que piensa hubiera prevalecido en ausencia de la correspondiente actuación. Toda actividad humana, en este sentido, viene siempre dictada por el egoísmo. Quien entrega dinero para alimentar niños hambrientos lo hace porque piensa que su acción será premiada en la otra vida o porque disfruta más remediando la necesidad infantil que con cualquier otra satisfacción que el dinero en cuestión pudiera conseguirle. El político también es egoísta; tanto cuando, para alcanzar el poder, hace suyas las ideas más populares; como cuando se mantiene fiel a sus propias convicciones despreciando las ventajas y beneficios que conseguiría si traicionara tales ideas.

\section{CONCLUSIONES}

La mentalidad anticapitalista -que considera la igualdad de ingresos y patrimonios como lo único natural y justo; que califica de explotador a quien tenga riquezas superiores a las del hombre medio; y que no acepta la actividad empresarial por considerarla perjudicial al bien común- utiliza los conceptos egoísta y altruista, de acuerdo con lo que le sugiere tal mentalidad. El burócrata considera torpe y deshonesto el mundo de los negocios, el depender de los consumidores, el cortejar a la clientela, el obtener beneficio solo cuando se ha de conseguir atender a las masas compradoras mejor que la competencia. Gente noble y elevada -para el burócrata- son solo aquellos que aparecen en la nómina del gobierno.

Pero, desgraciadamente, no es angelical la condición de los funcionarios y sus dependientes; y pronto se dan cuenta que su decisiones, bajo un sistema intervencionista, pueden causar al empresario grandes pérdidas, $y$, a veces, también grandes ganancias. Hay empleados públicos rectos y honorables, pero también hay los que no dudan, si la cosa puede hacerse de un modo "discreto", en llevarse la parte de las "ganancias" que engendran sus autorizaciones. 


\section{Pablo Rivas Santos}

En muchas esferas, en un sistema intervencionista, es imposible evitar el favoritismo. Piénsese en la cuestión de las licencias de importación ¿A quién otorgarles y a quién denegarlas? No existe fórmula que permita hacer tal distribución de manera objetiva y libre de consideraciones personales. El que se llegue o no a pagar dinero por la adjudicación poco interesa, pues no es menos aceptable el sin cobrar nada; conceder las deseadas licencias a aquellos de quienes el gobierno espera conseguir en el futuro particulares servicios (sus votos electorales). El intervencionismo siempre engendra corrupción.

\section{BIBLIOGRAFÍA}

Mundell, Robert A. El hombre y la economía. 1978.

Reig, Joaquín; Velasco, Gustavo y Benegas Lynch, Alberto. Deliberaciones sobre la libertad. Centro de Estudios sobre la Libertad, 1980.

Rothbard Murray N. Moneda libre y controlada. Centro de Estudios sobre la Libertad, 1980.

Von Mises, Ludwig. Tratado de economía: acción humana. Fundación Ignacio Villalonga, 1981. 